\title{
Spectral aerosol extinction (SpEx): a new instrument for in situ ambient aerosol extinction measurements across the UV/visible wavelength range
}

\author{
C. E. Jordan ${ }^{1, a}$, B. E. Anderson ${ }^{2}$, A. J. Beyersdorf ${ }^{2}$, C. A. Corr ${ }^{2,3}$, J. E. Dibb ${ }^{1}$, M. E. Greenslade ${ }^{4}$, R. F. Martin ${ }^{2}$, \\ R. H. Moore ${ }^{2}$, E. Scheuer ${ }^{1}$, M. A. Shook ${ }^{2,5}$, K. L. Thornhill ${ }^{2,5}$, D. Troop ${ }^{6}$, E. L. Winstead ${ }^{2,5}$, and L. D. Ziemba ${ }^{2}$ \\ ${ }^{1}$ Institute for the Study of Earth, Oceans, \& Space, University of New Hampshire, Durham, NH, USA \\ ${ }^{2}$ NASA Langley Research Center, Hampton, VA, USA \\ ${ }^{3}$ Oak Ridge Associated Universities, Oak Ridge, TN, USA \\ ${ }^{4}$ Department of Chemistry, University of New Hampshire, Durham, NH, USA \\ ${ }^{5}$ Science Systems and Applications, Inc., Hampton, VA, USA \\ ${ }^{6}$ Southwest Research Institute, Durham, NH, USA \\ ${ }^{a}$ now at: National Institute of Aerospace, Hampton, VA, USA
}

Correspondence to: C. E. Jordan (carolyn.jordan@ nianet.org)

Received: 7 April 2015 - Published in Atmos. Meas. Tech. Discuss.: 29 June 2015

Revised: 23 October 2015 - Accepted: 27 October 2015 - Published: 11 November 2015

\begin{abstract}
We introduce a new instrument for the measurement of in situ ambient aerosol extinction over the 300$700 \mathrm{~nm}$ wavelength range, the spectral aerosol extinction (SpEx) instrument. This measurement capability is envisioned to complement existing in situ instrumentation, allowing for simultaneous measurement of the evolution of aerosol optical, chemical, and physical characteristics in the ambient environment. In this work, a detailed description of the instrument is provided along with characterization tests performed in the laboratory. Measured spectra of $\mathrm{NO}_{2}$ and polystyrene latex spheres (PSLs) agreed well with theoretical calculations. Good agreement was also found with simultaneous aerosol extinction measurements at 450, 530, and $630 \mathrm{~nm}$ using CAPS PMex instruments in a series of 22 tests including nonabsorbing compounds, dusts, soot, and black and brown carbon analogs. SpEx measurements are expected to help identify the presence of ambient brown carbon due to its $300 \mathrm{~nm}$ lower wavelength limit compared to measurements limited to longer UV and visible wavelengths. Extinction spectra obtained with SpEx contain more information than can be conveyed by a simple power law fit (typically represented by Ångström exponents). Planned future improvements aim to lower detection limits and ruggedize the instrument for mobile operation.
\end{abstract}

\section{Introduction}

Over the past decade, studies of aerosol optical properties have become an important topic of research motivated by large uncertainties that limited our predictive capabilities of climate (IPCC, 2007). While our climate predictions have become more robust in recent years, radiative forcing (RF) by aerosols "continue to contribute the largest uncertainty to the total RF estimate" (IPCC, 2014). As work has progressed in recent years via modeling, laboratory studies, ambient measurements, and satellite retrievals, complicated relationships have been revealed between aerosol primary sources and secondary production and processing mechanisms. Aerosol composition, particle size and shape, the mixing state of an aerosol population, and particle number concentrations all play a role in the optical properties of aerosols in the ambient atmosphere. Hence, many efforts are underway to investigate these features in ambient aerosols to better characterize their optical properties, in the hopes of reducing uncertainties in calculating the Earth's radiation budget. Conversely, it has also been suggested that optical properties retrievals hold promise for remotely sensing aerosol size and composition throughout the global troposphere as well as to forecast regional- and local-scale air quality. 
Aerosols interact with light both through scattering and absorption; the sum of these is known as extinction. This interaction is wavelength $(\lambda)$-dependent, often characterized by a power law, where the Angström exponent $(\alpha)$ is the power that defines the slope of that relationship to wavelength (Ångström, 1929; Moosmüller and Chakrabarty, 2011):

$p(\lambda)=\lambda^{-\alpha}$,

where $p(\lambda)$ represents any parameter that can be represented with a power law. Ambient aerosol optical properties (extinction, scattering, and absorption) are each represented in this way. Many currently available commercial aerosol instruments (e.g., laser-based methods) obtain these parameters at relatively few (three or fewer) visible wavelengths. For these instruments, $\alpha$ is calculated for two wavelengths $\left(\lambda_{1}, \lambda_{2}\right)$ and it is assumed that a power law represents the full wavelength range between those two endpoints (Moosmüller and Chakrabarty, 2011), e.g.,

$$
\begin{aligned}
& \frac{p\left(\lambda_{1}\right)}{p\left(\lambda_{2}\right)}=\left(\frac{\lambda_{1}}{\lambda_{2}}\right)^{-\alpha}, \\
& \alpha\left(\lambda_{1}, \lambda_{2}\right)=-\frac{\ln \left(p\left(\lambda_{1}\right) / p\left(\lambda_{2}\right)\right)}{\ln \left(\lambda_{1} / \lambda_{2}\right)} .
\end{aligned}
$$

However, there is evidence that other mathematical relationships (e.g., nonlinear expressions to account for curvature in log space) may offer a better fit for certain optical parameters of specific types of aerosol over particular wavelength ranges (e.g., Eck et al., 1999; Schuster et al., 2006). This suggests that extrapolating $\alpha$ to wavelengths outside of the measured range may be problematic, especially when extrapolating into the UV from measurements made at visible wavelengths. Hence, observations at several wavelengths (or over a broad range of wavelengths) particularly into the UV, would be useful in more fully characterizing wavelengthdependent optical properties of ambient aerosols (Laskin et al., 2015).

Wavelength-dependent optical properties are used to distinguish four aerosol types from each other: black carbon (BC), brown carbon (BrC), dust, and nonabsorbing aerosols. The wavelength dependence of aerosol light scattering depends on the size distribution and particle shape, and less on the chemical composition of the aerosol. Aerosol light absorption, however, depends heavily on the chemical or molecular structure within the particles. BC is the strongest absorber of visible light, with its absorption characterized by $\alpha_{\text {abs }} \sim 1$ (e.g., Yang et al., 2009; Desyaterik et al., 2013; Bond et al., 2013). This wavelength dependence arises from the molecular structure of $\mathrm{BC}$, which is emitted with a graphite-like sheet structure (Bond and Bergstrom, 2006; Yang et al., 2009). Such structures feature many $\pi$-bonded carbon atoms with delocalized electrons that readily absorb light across the ultraviolet (UV) through infrared (IR) wavelength range (Desyaterik et al., 2013), giving rise to the black color of soot. The graphitic sheets fold into spherules that then rapidly coagulate into loose aggregates, small enough with respect to visible and near-visible wavelengths that their interaction with light falls within the Rayleigh regime, i.e., $\alpha_{\text {abs }} \sim 1$ (Yang et al., 2009). In this regime, refractive indices are assumed to be wavelength-independent (Moosmüller and Chakrabarty, 2011, and references therein).

In contrast, BrC (light-absorbing organic carbon) has far fewer conjugated $\pi$ electrons to absorb light. The wavelength range of absorption depends on the number of conjugated bonds in a molecule, along with the presence of heteroatoms, e.g., $\mathrm{O}$ or $\mathrm{N}$, such that more bonds or heteroatoms shift the absorption to longer wavelengths (e.g., Jacobson, 1999; Apicella et al., 2004; Chen and Bond, 2010). Where $\mathrm{BC}$ has many such bonds, absorption occurs into the IR wavelength range, but for $\mathrm{BrC}$ absorption is limited to $\mathrm{UV}$ and visible wavelengths. Aromatic rings offer a stable structure for conjugated bonds in atmospheric molecules; however a single ring has too few bonds to absorb light in the near-UV or visible range. Substituted $\mathrm{O}$ or $\mathrm{N}$ molecules on a single ring, or multiple rings (i.e., polycyclic aromatic hydrocarbons, PAHs) shift the absorption into the UV/visible range, leading to a characteristic wavelength dependence for these $\mathrm{BrC}$ aerosols that features strong UV absorption such that $\alpha_{\mathrm{abs}}>1$ (Andreae and Gelencsér, 2006; Moosmüller et al., 2009; Chen and Bond, 2010; Desyaterik et al., 2013). This results in $\mathrm{BrC}$ exhibiting a yellow-to-brown color, hence the term "brown carbon". BrC may be expected to optically evolve in the atmosphere since terminal double bonds (and heteroatoms) are more susceptible to atmospheric oxidant attack, thereby reducing the number of conjugated $\pi$ electrons in the molecules that comprise BrC. Conversely, secondary organic aerosol (SOA) formation from oxidation products with suitable structure may lead to $\mathrm{BrC}$ formation in the atmosphere.

Dust particles are more weakly absorbing per mass in the mid-visible than either $\mathrm{BC}$ or $\mathrm{BrC}$, but are important absorbers in the atmosphere due to the mass of material emitted (Bond et al., 2013). The optical properties of dust depend on its mineral composition, particle shape, aerosol size distribution, and modifications during atmospheric transport (Yang et al., 2009). Dust that contains iron oxides and clay is known to significantly absorb light in the UV/visible range (Sokolik and Toon, 1999), with reports of $\alpha_{\text {abs }}$ up to $\sim 3$ over 325$660 \mathrm{~nm}$ (Alfaro et al., 2004; Yang et al., 2009). Many other organic and inorganic compounds in aerosols do not absorb light and are classified optically as nonabsorbing (or pure scattering) aerosols, e.g., polystyrene latex spheres (PSLs), ammonium sulfate (AS), and sea salt (Washenfelder et al., 2013).

The characteristic wavelength dependence of absorption distinguishes these groups from each other. Extinction, however, includes the effects of both scattering and absorption, where scattering dominates the two contributions. For example, even though dust may have $\alpha_{\text {abs }} \sim 3$, the large size (typically supermicron diameters) of dust particles results in $\alpha_{\text {scat }}$ 
near 0 , leading to $\alpha_{\mathrm{ext}} \sim 0$. For the other three groups, with smaller (submicron diameter) particle sizes that may be comparable to each other in the ambient atmosphere, the scattering contribution may be expected to be similar, while the absorption contribution will clearly differ. In visible wavelengths, the relative difference in absorption may be difficult to discern from the much larger scattering term when measuring extinction. However, in the UV, particularly at wavelengths as short as $300 \mathrm{~nm}$, the absorption term may influence the shape of the extinction spectrum revealing differences among these groups.

Of these four groups of optically defined aerosols, $\mathrm{BrC}$ may be the most complex to quantify with myriad potentially important sources identified in the literature (see the recent review by Laskin et al., 2015, and references therein). Sources of BrC include combustion (biogenic and fossil fuels), humic-like substances, and SOA compounds that are derived from anthropogenic and biogenic precursors (e.g., Andreae and Gelencsér, 2006; Hecobian et al., 2010). Identifying the specific compounds that contribute to $\mathrm{BrC}$ is challenging. Several studies have examined the absorption properties of solution-phase extracts (e.g., in water, methanol, or hexane solvents; e.g., Chen and Bond, 2010; Hecobian et al., 2010; Zhang et al., 2011, 2013); however, the solubility of the compounds in each solvent determines which compounds are extracted, and hence, the wavelength dependence will reflect the compounds in solution. Other factors will also affect solution-phase absorption, beyond the choice of solvent, which include the degree of dilution (Zhang et al., 2013), pH (Jacobson, 1999), and degree of dissolution (i.e., ionic versus molecular forms) (Jacobson, 1999).

Given that different sources have been identified for $\mathrm{BrC}$, where mixtures from various sources occur (whether primary organic aerosol (POA), SOA, or both), photooxidative competition among the compounds present may be expected to lead to differing evolution of $\mathrm{BrC}$ in the atmosphere. In some cases, photooxidation may reduce $\mathrm{BrC}$ over time; in others it may produce BrC. Since not all SOA-forming products absorb light and those that do absorb at varying peak wavelengths and at varying strengths (e.g., Jaoui et al., 2008; Zhang et al., 2011), it is expected that BrC formation, evolution, and destruction in the atmosphere may be highly variable. It must also be noted that chromophores may comprise a minor fraction of ambient aerosol mass, such that large changes in optical properties with aerosol age are not necessarily accompanied by large changes in mass spectra, or Fourier transform infrared (FTIR) or nuclear magnetic resonance (NMR) spectra (Bones et al., 2010). Hence, tools are needed to assess the optical evolution of ambient aerosols, along with tools used to investigate their chemical and physical qualities.

In addition to contributing to studies of ambient aerosol optical, physical, and chemical evolution, directly measured aerosol extinction is expected to be useful for studies of other important optical information as well. For example, single- scatter albedo $(\omega(\lambda))$ is a measure of the fraction of light scattered from the total extinction defined by the ratio of the scattering coefficient $\left(\sigma_{\text {scat }}(\lambda)\right)$ to the extinction coefficient $\left(\sigma_{\text {ext }}(\lambda)\right)$,

$\omega(\lambda)=\frac{\sigma_{\text {scat }}(\lambda)}{\sigma_{\text {ext }}(\lambda)}=\frac{\sigma_{\text {scat }}(\lambda)}{\left(\sigma_{\text {scat }}(\lambda)+\sigma_{\text {abs }}(\lambda)\right)}$,

where $\sigma_{\text {ext }}(\lambda)$ may also be expressed as the sum of $\sigma_{\text {scat }}(\lambda)$ and the absorption coefficient $\left(\sigma_{\mathrm{abs}}(\lambda)\right)$. This is an intensive property of a particle, a function of its composition and independent of total aerosol concentration (Yang et al., 2009). For nonabsorbing particles, $\omega=1$ at all wavelengths. This parameter is used in models to determine the sign and magnitude of RF (Moosmüller and Chakrabarty, 2011). Often for in situ measurements, scattering is measured (e.g., nephelometry) and absorption is measured (e.g., aethalometry), then summed to obtain extinction for the calculation of $\omega(\lambda)$. Commercially available instruments are also available for the direct measurement of extinction. However, these measurements are restricted to visible wavelengths and are often at a few (one to three) wavelengths. See Washenfelder et al. (2013) for a recent synopsis of various measurement techniques for aerosol scattering, absorption, and extinction. Direct extinction measurements of $\sigma_{\text {ext }}(\lambda)$ over both the UV and visible range would provide a useful addition to current measurement techniques for the calculation of $\omega(\lambda)$.

With this motivation, to investigate linkages between ambient aerosol chemistry, physical attributes, and optical properties, the instrument to study spectral aerosol extinction across the UV/visible range (abbreviated SpEx) has been developed. In this work we introduce the new instrument and show laboratory test results performed at NASA Langley Research Center in March 2014 that characterize both the instrument performance as well as spectral properties of various laboratory-generated aerosols. The rack-mounted prototype configuration was deployed aboard the ground-based NASA Langley Mobile Aerosol Characterization (MACH2) laboratory during DISCOVER-AQ (Deriving Information on Surface conditions from Column and Vertically Resolved Observations Relevant to Air Quality) and obtained ambient spectra while parked at several ground sites. A subsequent paper will present data obtained during the DISCOVER-AQ Colorado field campaign in July/August 2014.

\section{Experimental}

Tests were performed with a calibrated $\mathrm{NO}_{2}$ standard as well as laboratory-generated aerosols to characterize the new instrument. A detailed description of SpEx follows, along with brief descriptions of the other instruments used to validate the new technique. 


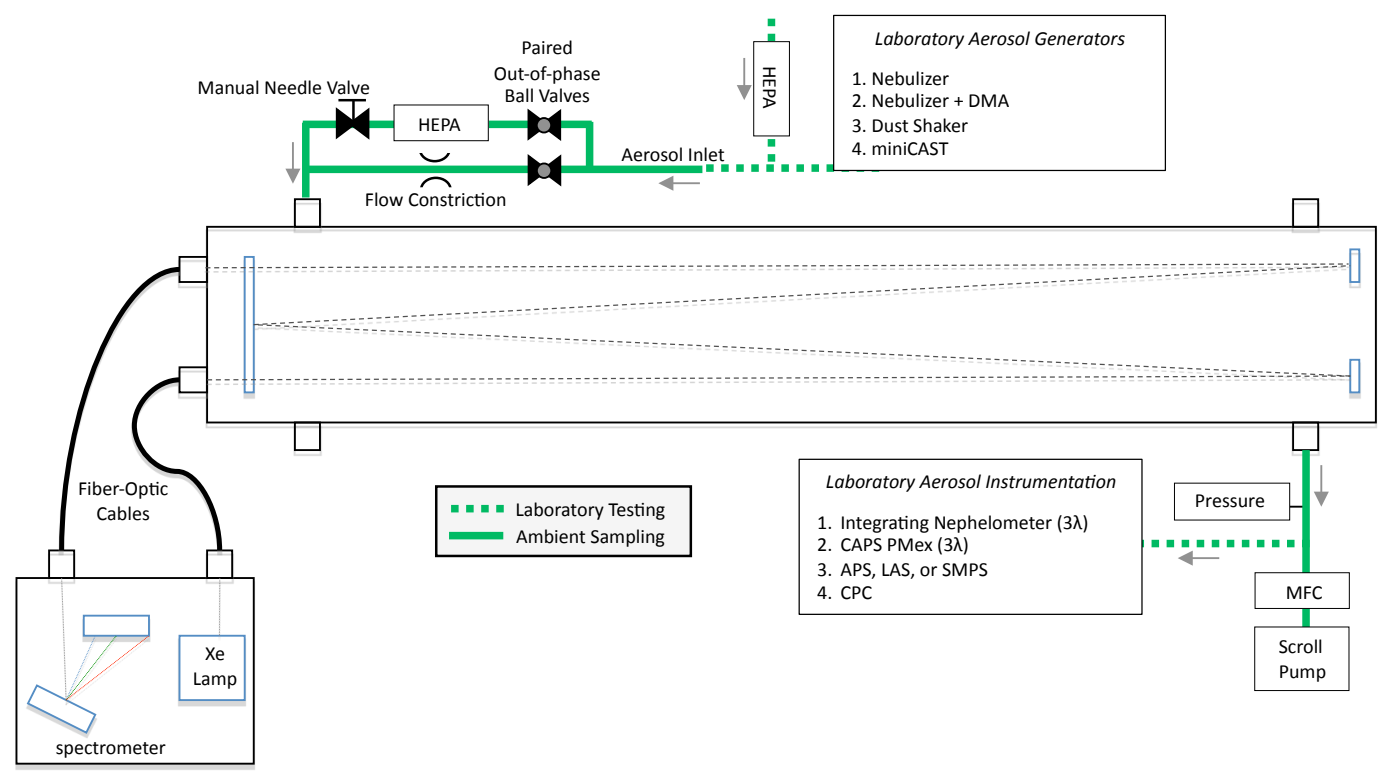

Figure 1. Schematic of SpEx, along with other instrumentation used in the laboratory experiments. The laboratory aerosol instrumentation downstream of the optical cell sampled from a common manifold.

\subsection{SpEx description}

$\mathrm{SpEx}$ is a modified version of the aerosol extinction differential optical absorption spectrometer (AE-DOAS), a custombuilt instrument that has been used in laboratory studies (Chartier, 2010; Chartier and Greenslade, 2012). Development of SpEx adopted the measurement approach of AEDOAS with improvements to allow for faster data acquisition and enhanced sensitivity. These instruments use a White-type optical cell (White, 1942) in which the primary and two secondary concave mirrors have the same radius of curvature separated by a distance of twice the focal length. Light intensity in the cell (with an optical path length, $L$ ) is measured for a sample (air with aerosols, $I$ ) and for a reference (filtered air, $I_{0}$ ) allowing for the calculation of aerosol extinction via Beer's Law:

$\sigma_{\mathrm{ext}}=\frac{-\ln \left(I / I_{0}\right)}{L}$.

Extinction is expressed in units of inverse length. For convenience, in the ambient atmosphere, the units typically used are inverse megameters $\left(\mathrm{Mm}^{-1}\right)$.

These instruments (AE-DOAS and $\mathrm{SpEx}$ ) are comprised of three key components coupled with fiber optics: a broadband xenon lamp, a closed White-type multi-pass cell, and a spectrometer. The main improvements to AE-DOAS are detailed here and include a longer optical path length and a 16bit spectrometer to improve sensitivity; larger orifices to allow for faster flow rates, more rapid air exchange in the cell, and hence faster data acquisition; automated operation for $24 \mathrm{~h}$ sampling in the field that includes flow control, switching between filtered and unfiltered lines, and data acquisition.
SpEx offers a rack-mountable design for field studies of ambient aerosol monitoring.

SpEx (Fig. 1) was custom-designed based on the UV 5000 gas analyzer system (Cerex Monitoring Solutions, LLC, Atlanta, GA) with a $150 \mathrm{~W}$ xenon lamp source (Cerex P/N CRX-X150W), integrated with an Ocean Optics, Inc. (Dunedin, FL) QE65Pro 16-bit spectrometer. These components are coupled with $600 \mu \mathrm{m}$ fiber optic cables to a customdesigned White-type optical cell fabricated by Cerex Monitoring Solutions, LLC., out of aluminum with rectangular dimensions of $6^{\prime \prime} \times 4.25^{\prime \prime} \times 56.18^{\prime \prime}(15.24 \times 10.8 \times 142.7 \mathrm{~cm})$ and an internal volume of approximately $17 \mathrm{~L}$. The QE65Pro includes their standard 1024 pixel detector and a composite grating providing 1.36 pixels per nm over a range of $750 \mathrm{~nm}$ starting at $200 \mathrm{~nm}$, resulting in a spectral resolution of approximately $0.7 \mathrm{~nm}$. The built-in cooling system of the spectrometer allows the detector to be cooled down to $-20^{\circ} \mathrm{C}$ to minimize noise. The fiber optic cables are $2 \mathrm{~m}$ long with heavy-duty metal jacketing.

Constructed from a rectangular tube, two ports were cut in the top of the cell above the optics to allow for adjusting the optical alignment. Four side ports, two at each end, allow for flexible configuration of air inflow and outflow ports for rack mounting. For laboratory and ambient sampling (Fig. 1), ports on opposite sides were used to maximize mixing in the cell and to ensure that air flows across the optical path. Halfinch $(1.27 \mathrm{~cm})$ conductive silicone inlet tubing allowed for flow rates up to $80 \mathrm{~L} \mathrm{~min}^{-1}$ for rapid air exchange within the volume, and were actively controlled using a mass-flow controller (MFC). To ensure complete air exchange between the sample and reference air within the optical cell, a flush 
volume of at least 3 times the internal volume of the cell $(17 \mathrm{~L} \times 3=51 \mathrm{~L})$ must be used. At $80 \mathrm{~L} \mathrm{~min}^{-1}$ this takes approximately $40 \mathrm{~s}$. In the laboratory tests, a flush time of $90 \mathrm{~s}$ was used, with the particle counts in the outflow of the optical cell monitored to ensure the air was fully exchanged between the sample (unfiltered) and reference (filtered) lines, which were autonomously cycled using a pair of electrically actuated, straight-path ball valves. The change in pressure, measured downstream of the sample cell, when switching from sample and reference lines, was minimized (to less than 1 torr) by slightly restricting flow in the sample line and manually setting the filter-line pressure drop (at a constant flow rate) using a needle valve. This allowed accurate measurements and negligible particle transmission loss.

The White-type cell (Fig. 1) is designed to allow for a range of optical path lengths. As is evident from Eq. (4), for any given difference between $I$ and $I_{0}$, a longer path length $(L)$ offers greater sensitivity in extinction, while for any given path length, maximizing $I_{0}$ improves sensitivity of $\sigma_{\text {ext }}$ to $I$. With a 48 -inch $(1.23 \mathrm{~m})$ basepath between mirrors, an alignment with six spots across the top of the primary mirror (28 passes total) provides an optical path length of $34.4 \mathrm{~m}$, while the maximum of eight spots ( 36 passes total) extends the path to $44.3 \mathrm{~m}$. Since a little light is lost at each reflection of the light beam, intensity decreases as the path length (i.e., the number of spots) increases. Hence, determining the optimum path length requires a balance in maximizing the intensity versus maximizing the number of spots. In tests at Cerex Monitoring Solutions, seven spots (32 passes total) were found to offer the optimum path length of $39.4 \mathrm{~m}$, given the light source and the efficiency of the mirror coatings over the UV/visible range. Note that the optical path results in two rows of light spots on the primary mirror. Notches cut out of the top half of the primary mirror at either end allow incoming and outgoing light to enter and exit the cell via the fiber optic ports. Collimating lenses focus the light as it enters and exits the cell.

As this is a broadband light source, the spot size is large (on the order of $1 \mathrm{~cm}$ ). Longer wavelengths of the light wave are toward the center of the spot, while the shorter wavelengths are toward the outside of the spot. Since the spot is larger than the fiber diameter $(600 \mu \mathrm{m})$, as the mirror alignment is adjusted slightly, the sampled spectrum from the light source may be optimized. Tuning results in large changes in the measured intensity spectrum for the same optical path length. Here, the QE65Pro records the lamp intensity from 200 to 995 nm (Fig. S1 in the Supplement). The spectral characteristics of the lamp and the mirror coatings are such that wavelengths between 200-250 and 750-800 nm exhibit low intensity, while those $>800 \mathrm{~nm}$ tend to be most intense. In order to optimize for sampling over the 300-700 $\mathrm{nm}$ wavelength range, the spectral sampling is adjusted to maximize the intensity over that range, while the integration time is set such that the infrared channels saturate (Fig. S1). When properly aligned, an integration time of 20-50 ms maximizes

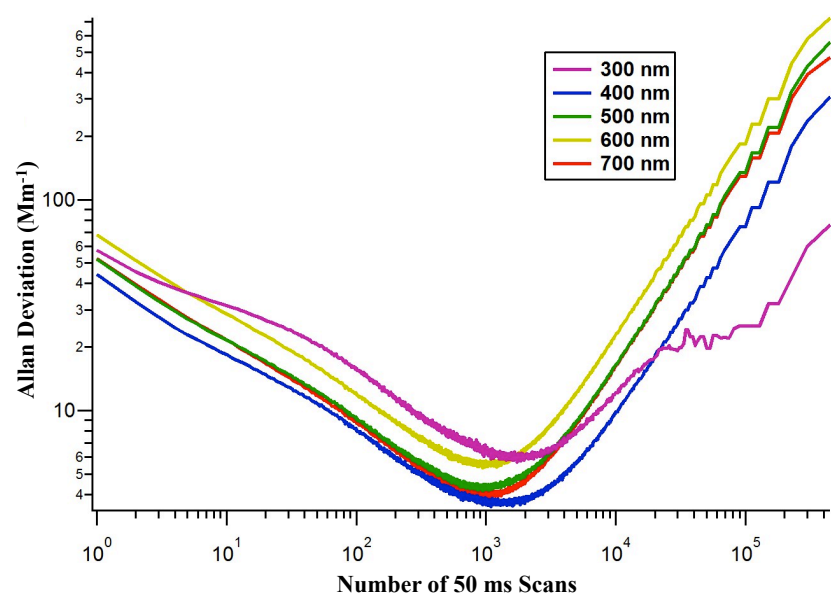

Figure 2. Allan variance plot for select wavelengths. Test conducted with filtered air at a flow rate of $90 \mathrm{~L} \mathrm{~min}^{-1}$ using $50 \mathrm{~ms}$ integration time per spectrum.

the intensity counts without saturation over the $300-700 \mathrm{~nm}$ range.

\subsection{SpEx operation, variance tests, and limit of detection}

For typical ambient atmospheric particle concentrations, extinction represents a small difference between two large numbers, $I$ and $I_{0}$. As a result, care must be taken to minimize sampling bias and noise. Prior to any sample collection, the instrument is turned on and allowed to warm up for $\sim 1 \mathrm{~h}$ to allow the lamp to thermally stabilize. Measured intensity may drift slightly between spectra (typically < $1 \%$ ). This may arise from thermal variability of the lamp (which was not temperature-controlled for these tests), temperature variations of the gas cell, inducing minor fluctuations of the optics, or variability in the power source for the lamp. To limit any variability in the extinction calculation that may arise from a drift in intensity, the extinction is automatically calculated by averaging the reference spectra collected immediately prior to and following a given sample spectra.

Noise arises in optical instrument systems both from highand low-frequency sources that can be characterized by an Allan variance calculation. Such a calculation is used to identify the optimum sampling interval, i.e., sampling over too few spectra results in noise from high-frequency sources, while sampling over too many results in noise from lowfrequency sources. A plot of Allan variance shows the optimum sample size to minimize noise in the signal. Using an integration time of $50 \mathrm{~ms}$ per spectrum (the upper end of the range used for sampling prior to realigning the optics) and a flow rate of $90 \mathrm{~L} \mathrm{~min}^{-1}$, filtered air was pulled through the system and spectra were acquired in a $13 \mathrm{~h}$ test. The Allan deviation of the average versus the number of scans shows that for $\mathrm{SpEx} \sim 1000$, spectra provide the best sensitivity over the 
300-700 nm wavelength range (Fig. 2), resulting in Allan deviations of $\pm 3.5-5.7 \mathrm{Mm}^{-1}$ (Table $\mathrm{S} 1$ in the Supplement).

At $50 \mathrm{~ms}$, it takes $50 \mathrm{~s}$ to collect 1000 spectra. From Fig. 2 however, it is evident that fewer spectra can offer sensitivity nearly as well, while allowing for faster data acquisition. On the basis of laboratory tests (data not shown) and the Allan variance calculations, it was found that a $30 \mathrm{~s}$ sampling time provided good sensitivity with low noise. For 600 spectra (30 s sampling time for $50 \mathrm{~ms}$ integration) the Allan variance was $\pm 4.1-7.6 \mathrm{Mm}^{-1}$ over $300-700 \mathrm{~nm}$. Intensity spectra were acquired at a temporal resolution of $125 \mathrm{~s}$ (90 s flush, $30 \mathrm{~s}$ sample, plus a $5 \mathrm{~s}$ delay added to allow time for valves to open and close to switch between the filtered and unfiltered lines). As a result, aerosol extinctions were obtained with a $250 \mathrm{~s}$ time resolution.

These data suggest a $3 \sigma$ limit of detection of $\sim 12$ $23 \mathrm{Mm}^{-1}$ over $300-700 \mathrm{~nm}$ wavelengths for the individual laboratory spectra presented here. This detection limit is adequate for ambient aerosol measurements in most ambient boundary layer environments (typical mid-visible scattering is $57 \mathrm{Mm}^{-1}$ for average background environments and $23 \mathrm{Mm}^{-1}$ for clean continental background environments, Seinfeld and Pandis, 1998). For ground-based measurements in clean continental environments, by making use of the standard error of the mean, individual extinction spectra may be averaged, thereby reducing the error by the square root of the number of samples in the mean. Hourly averages (16 spectra) have the effect of reducing the error by a factor of 4 , thereby reducing the detection limit to $3-6 \mathrm{Mm}^{-1}$ over the 300 $700 \mathrm{~nm}$ range. Thus, this data reduction scheme is able to sufficiently characterize both concentrated plumes and background conditions on reasonable timescales at ground sites. Future modifications to SpEx are anticipated to reduce the limit of detection such that airborne deployments for measurements in the free troposphere will be feasible.

\subsection{Validation instruments}

The Cavity Attenuated Phase Shift extinction (CAPS PMex) monitor, manufactured by Aerodyne Research, is an optical extinction spectrometer which has a light-emitting diode (LED) as a light source, a $26 \mathrm{~cm}$ long sample cell with two high reflectivity mirrors and a vacuum photodiode detector. Due to its configuration, the cell cavity has an effective path length of approximately $2 \mathrm{~km}$. Similar in principle to a cavity ring-down instrument, the CAPS PMex monitor relies on measuring the average time spent by the light within the sample cell. Particles in the cell decrease this time due to scattering and absorption. The particle light extinction is determined from changes in the phase shift of the distorted waveform of the square-wave-modulated LED light that is transmitted through the optical cell. Three CAPS PMex monitors were used with differing wavelengths $(450,530$, and $630 \mathrm{~nm})$. The CAPS PMex particle optical extinction mon- itor has a range of $0-4000 \mathrm{Mm}^{-1}$, resolution of $0.1 \mathrm{Mm}^{-1}$ and a sensitivity of $2.5 \mathrm{Mm}^{-1}$ in a $1 \mathrm{~s}$ sampling period.

The TSI Inc. Integrating Nephelometer (model 3563) measures aerosol scattering at three visible wavelengths $(450$, 550 , and $700 \mathrm{~nm}$ ) for the total angular range between 7 and $170^{\circ}$. The measurement can be corrected for truncation (i.e., the missing scattering not measured for angles 0-7 and 170$180^{\circ}$ ) based on Anderson and Ogren (1998). The instrument was regularly zeroed with particle-free air and calibrated with $\mathrm{CO}_{2}$. Scattering is measured at $1 \mathrm{~Hz}$ and a sensitivity of $0.1 \mathrm{Mm}^{-1}$ for a $60 \mathrm{~s}$ averaging period.

\subsection{Aerosol generation}

Dust aerosol samples were generated by a Wrist Action Shaker (Burrell model 75) with the speed varied to change the aerosol concentration. The motion of the shaker suspends the dust into the sample air stream via saltation (Kumar et al., 2011). The dust was either sampled as produced or through a stainless steel cyclone (URG) with a 1 micron cut at $10 \mathrm{~L} \mathrm{~min}^{-1}$. The flow through the cyclone could be changed to result in a differing aerosol size distribution. Changes between the $\mathrm{PM}_{1}$ and $\mathrm{PM}_{2.5}$ tests described in Sect. 3 were verified with an Aerodynamic Particle Sizer (APS, TSI, Inc. model 3321). Soot samples were generated by a quenched propane burner (miniCAST Series 4202, Jing Ltd.) with variable nitrogen-to-fuel ratios used to vary soot size and soot composition (Moore et al., 2014). Liquid aerosols were generated from aqueous solutions by a TSI Inc. aerosol nebulizer (model 3076). In all cases the generators did not produce enough flow $\left(1-10 \mathrm{~L} \mathrm{~min}^{-1}\right)$ to accommodate all the instrumentation, so particle-free air was added to the output from the aerosol generators. For some tests, aerosols were sizeselected using a differential mobility analyzer (DMA, TSI Inc. model 3081). For these size-selected tests, we did not correct the size distributions for multiply charged particles, as all compounds selected at the same size using the same flow rates will have similar percentages of multiply charged species, resulting in a similar size distribution for all cases. Particle number concentrations were measured (by a condensation particle counter, CPC, TSI 3775) to verify sufficient flush timing and to verify constant test conditions. Measurements of size distributions of submicron (by a scanning mobility particle sizer, SMPS, TSI) and supermicron (by a laser aerosol spectrometer, LAS, TSI Inc.) aerosols during laboratory testing were used to confirm the generated aerosol characteristics. 


\section{Results}

\subsection{Accuracy of measured spectra}

\subsection{1 $\mathrm{O}_{2}, \mathrm{NO}_{2}$, and PSL tests}

Laboratory tests were designed to document the accuracy of SpEx extinction spectra by assessing (1) whether the filter used to remove the aerosols also removed $\mathrm{NO}_{2}$ such that measured spectral characteristics include gas-phase differences unrelated to aerosol extinction, (2) whether the intense UV lamp light photolyzed $\mathrm{NO}_{2}$ to $\mathrm{O}_{3}$ in the optical cell, and (3) whether the measured spectral shapes were consistent with expectations from theoretical calculations. $\mathrm{NO}_{2}$ efficiently absorbs light in the UV/visible range, motivating test no. 1. It is also readily photolyzed by UV light, making it useful for testing photolysis in the optical cell by the lamp (test no. 2).

$100 \mathrm{ppb} \mathrm{NO}$ (diluted from a calibrated cylinder of $5 \mathrm{ppm}$ $\mathrm{NO}_{2}$ ) was measured (using a Los Gatos Research instrument model 907) across the sample-line filter showing a negligible difference in mixing ratio between downstream and upstream locations, suggesting the filter is not modifying the $\mathrm{NO}_{2}$ concentration between the filtered and unfiltered sampling lines. Additional tests using both $\mathrm{O}_{3}$ (Thermo Environmental Instruments model $49 \mathrm{C}$ ozone analyzer) and $\mathrm{NO}_{2}$ showed that $\mathrm{O}_{3}$ is not being produced (conversely $\mathrm{NO}_{2}$ is not lost) in the optical cell by the light sources with $70-80 \mathrm{~L} \mathrm{~min}^{-1}$ flow. Minimal surface losses across the optical cell were found in both the $\mathrm{O}_{3}(9 \mathrm{ppb}$ in the cell vs. $15 \mathrm{ppb}$ in room air, on average) and $\mathrm{NO}_{2}$ (92 vs. $100 \mathrm{ppb}$ calibrated inflow) tests. However, the advantage of the difference method employed in the SpEx measurement is that gas-phase losses in the optical cell affect both the sample and reference lines in the same way, canceling each other out as long as ambient mixing ratios are constant throughout the full sample/background cycle.

Two sets of tests were performed, measuring absorption spectra of $\mathrm{NO}_{2}$ and extinction spectra of PSLs to verify measurements with theory. For $\mathrm{NO}_{2}$, a series of four tests were done starting with an undiluted $5 \mathrm{ppm}$ test from the calibrated cylinder, followed by a series of three dilutions $(1,250$, and $100 \mathrm{ppb}$ ). $\mathrm{NO}_{2}$ tests were performed by slowly filling the cell, capping it, then collecting spectra, in order to minimize the volume of calibration gas that would have been consumed with the $17 \mathrm{~L}$ volume and typical $80 \mathrm{~L} \mathrm{~min}^{-1}$ flow rate. Stopping the flow led to increased surface losses. Correcting the SpEx absorption spectra for these losses, it is clear that SpEx obtained a curve that captured the expected features calculated from GOME/SCIAMACHY $\mathrm{NO}_{2}$ cross-section data binned to $1 \mathrm{~nm}$ resolution (Fig. 3). Similar results were obtained in all four tests; only the $5 \mathrm{ppm}$ results are shown here. A minor offset of $\sim 1 \mathrm{~nm}$ in the SpEx absorption spectrum was found compared to the theoretical curve, requiring a correction of $+1 \mathrm{~nm}$ to the nominal $\mathrm{SpEx}$ wavelength. The comparison in Fig. 3 shows the ability of SpEx to capture
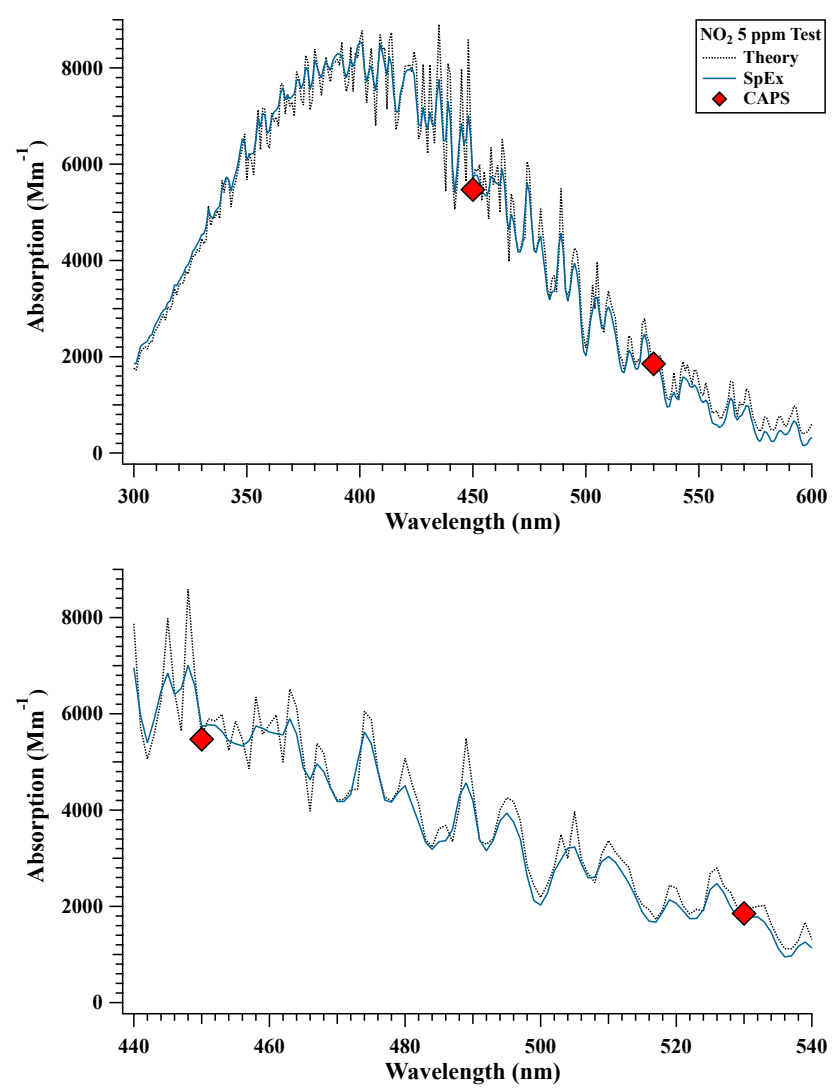

Figure 3. Theoretical $\mathrm{NO}_{2}$ absorption calculated from GOMESCIAMACHY cross sections averaged to $1 \mathrm{~nm}$ (dashed black line) compared with measured wavelength-corrected SpEx absorption binned to $1 \mathrm{~nm}$ (solid blue line), and CAPS PMex extinctions (red diamonds) from 300 to $600 \mathrm{~nm}$ (top panel). Detail of spectra from 440 to $540 \mathrm{~nm}$ are shown in the bottom panel.

the broad absorption peak centered around $400 \mathrm{~nm}$ over the $300-500 \mathrm{~nm}$ range, along with high-spectral-resolution features down to a few nanometers' width. In laboratory studies, similar high-resolution features in spectra of monodisperse aerosols have been used to retrieve refractive indices (e.g, Chartier and Greenslade, 2012).

The second set of tests measured the extinction spectra from 600 and $903 \mathrm{~nm}$ PSL spheres (Fig. 4). Mie theory calculations were performed with MiePlot v4.3 (http://philiplaven. $\mathrm{com} /$ mieplot.htm) using the wavelength-dependent refractive index for PSLs provided with that code. The wavelength dependence of the refractive index (Fig. 4, top panel) is consistent with results reported by Washenfelder et al. (2013) and references therein. The measured extinction spectra for 600 and $903 \mathrm{~nm}$ PSLs capture the structure of spectra (Fig. 4) calculated from the extinction cross sections $\left(C_{\text {ext }}\right.$, $\mathrm{m}^{2}$ particle ${ }^{-1}$ ). The $600 \mathrm{~nm}$ PSL spectra also agree well with that shown in Chartier (2010). Sensitivity tests of the Mie cross-section calculations to the particle radius and the dispersion of the aerosol size distribution show peaks in the 

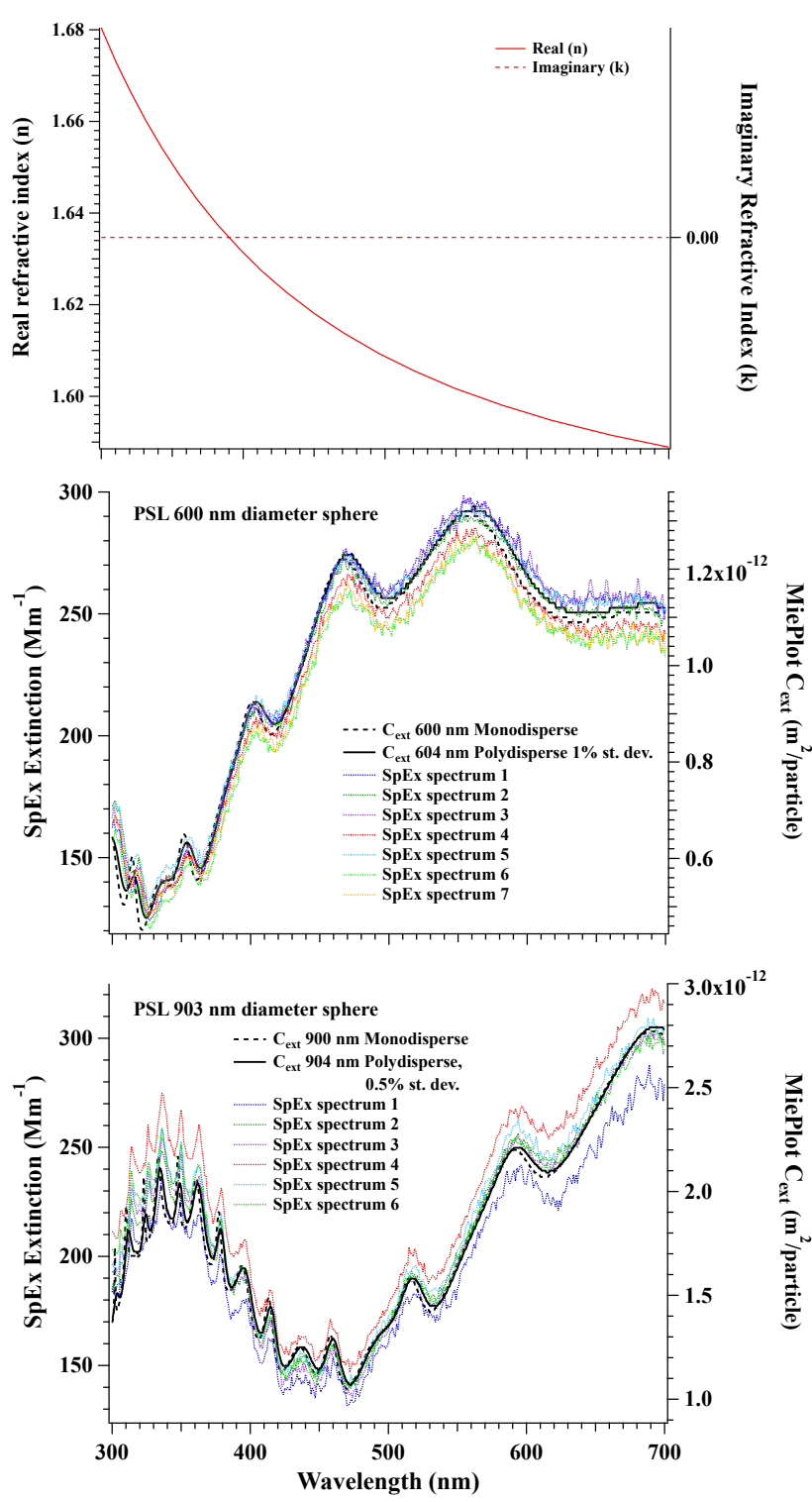

Figure 4. The wavelength-dependent refractive index for polystyrene latex spheres used in MiePlot (top panel). Extinction cross sections ( $C_{\text {ext }}, \mathrm{m}^{2}$ particle ${ }^{-1}$, right axes) calculated with MiePlot for two nominal sphere diameters: $600 \mathrm{~nm}$ (middle) and $900 \mathrm{~nm}$ (bottom) with curves for monodisperse size distributions (black dashed lines) and best fit curves (solid black lines), along with measured wavelength-corrected SpEx extinction spectra $\left(\mathrm{Mm}^{-1}\right.$, dotted colored lines, left axes). Several spectra were measured in each SpEx aerosol test, here seven spectra for PSL $600 \mathrm{~nm}$ and six spectra for PSL $903 \mathrm{~nm}$. Variability in the measured spectra arises from variability in the concentrations of aerosols generated over the course of each test.

extinction spectrum shift to longer wavelengths with increasing particle size, while the amplitude of the peaks flatten as the size distribution broadens (Fig. S2). The highspectral-resolution features in the spectral curves for these PSL tests arise from the monodisperse size distribution of these manufactured particles. For both the 600 and $903 \mathrm{~nm}$ particles, the best fit to the measured spectra was found using slightly larger particle diameters $(604$ and $904 \mathrm{~nm}$, respectively) and dispersions with 1 and $0.5 \%$ standard deviations, respectively (Fig. 4). These results are within the manufacturer calibration specifications for the two lots used here with $600 \pm 9 \mathrm{~nm}$ and $903 \pm 9 \mathrm{~nm}$ for the mean diameters with size distributions of $10.0 \mathrm{~nm}$ standard deviation; $1.7 \% \mathrm{CV}$ (coefficient of variance) and $9.3 \mathrm{~nm}$ standard deviation; and $1.0 \% \mathrm{CV}$, respectively.

\subsubsection{Comparison of SpEx with CAPS PMex extinction and nephelometer scattering}

Wavelength-dependent refractive indices are not known for many aerosols generated in the laboratory. In such cases, comparisons to other measurements are useful for testing the performance of the $\mathrm{SpEx}$ instrument. A series of tests were performed using a variety of laboratory-generated aerosols ranging from pure scatterers to various materials that absorb light (Table S2). Fullerene soot and Aquadag are commercially available and have been suggested to be used as surrogates for combustion-produced soot (Gysel et al., 2011; Baumgardner et al., 2012; Beyersdorf et al., 2014). All of the measured SpEx extinction spectra (30 s sampling period) were compared with extinction and scattering measured at three visible wavelengths by CAPS PMex $(450,530$, and $630 \mathrm{~nm})$ and nephelometer $(450,550$, and $700 \mathrm{~nm})$ instruments, respectively. CAPS PMex and nephelometer record $1 \mathrm{~s}$ data, which were averaged over the $30 \mathrm{~s}$ intervals coinciding with the SpEx sampling periods. The shape of the CAPS PMex and nephelometer curves in these tests (e.g., Fig. 5a and c) reflects the switching between filtered (zero extinction and scattering) and unfiltered (nonzero extinction and scattering), with each period about $2 \mathrm{~min}$ in length (90 s flush followed by $30 \mathrm{~s}$ sample collection by SpEx). CAPS PMex and nephelometer periodically zero, resulting in channels that occasionally switch between zero and sample values independently of the air flow through SpEx. Note, part of the offset between the nephelometer and CAPS PMex evident in Fig. 5a and $\mathrm{c}$ arises from the different wavelengths measured. However, in Fig. 5b good agreement (typically within $15 \%$ ) is found with the measured spectra from SpEx at each instrument's specific wavelengths.

Two examples from this series of aerosol tests are shown in Fig. 5: PSL $903 \mathrm{~nm}$ and Aquadag. Here, the SpEx extinction spectra are shown without any smoothing and are plotted using the nominal (rather than corrected) wavelengths. Most of the test data do not exhibit the high-spectral-resolution features evident in the PSL 600 and $903 \mathrm{~nm}$ tests. This is due to the relatively broad size distributions of the particles generated, compared to the monodisperse PSL particles. Hence, the $1 \mathrm{~nm}$ wavelength correction is likely insignificant for the majority of laboratory and ambient aerosols. For clarity, error bars of $\pm 6 \mathrm{Mm}^{-1}(1 \sigma)$ for the extinction spectra are not 

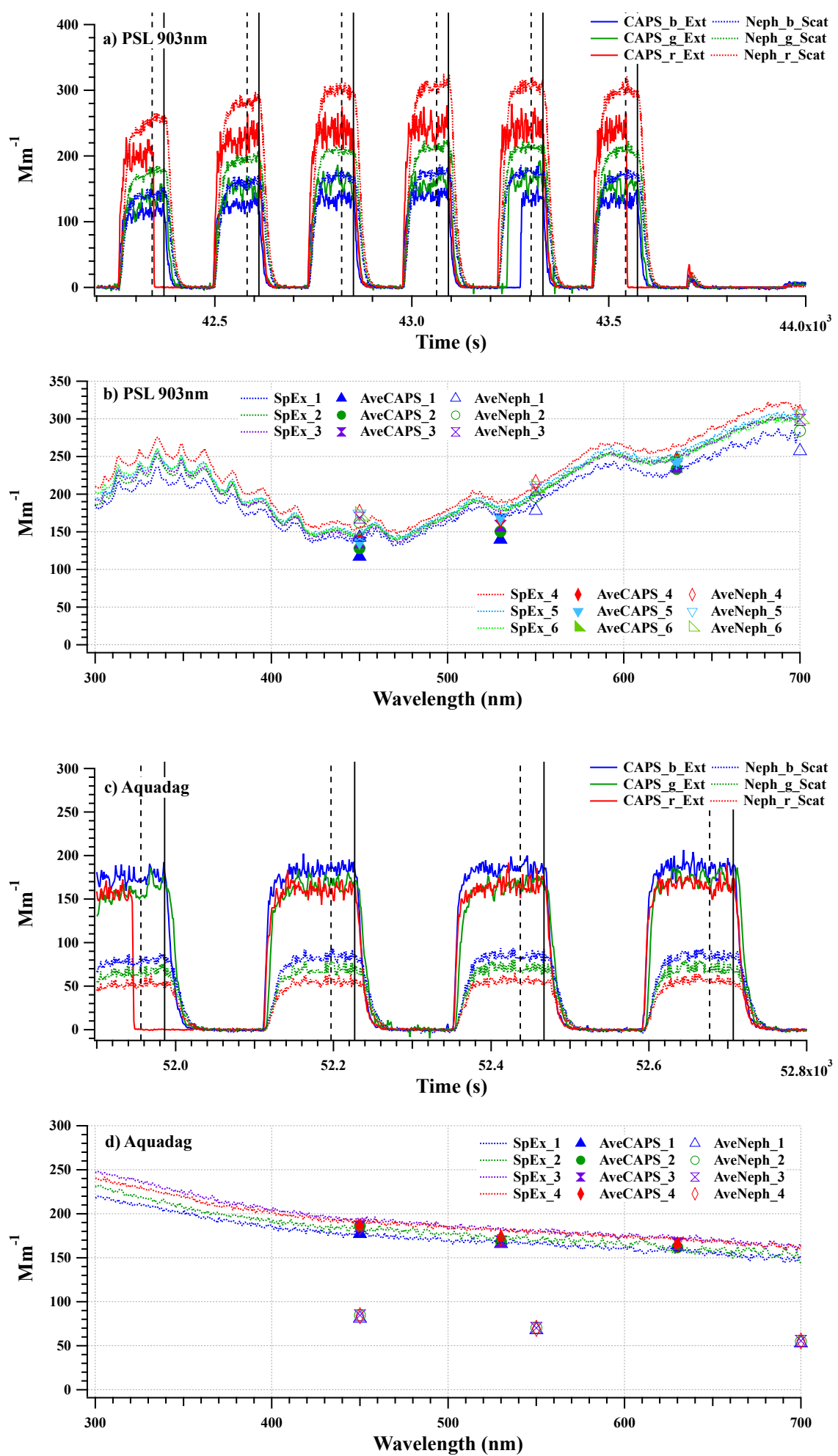

Figure 5. Examples of laboratory tests: PSL $903 \mathrm{~nm}$ (a and b) and Aquadag (c and d). One second CAPS PMex extinction (solid lines) and nephelometer scattering (dashed lines) at $450 \mathrm{~nm}$ for both (blue curves, b), 530 and $550 \mathrm{~nm}$, respectively (green curves, g), and 630 and $700 \mathrm{~nm}$, respectively (red curves, r) are shown in (a) and (c). SpEx extinction spectra are shown (b and d) with $30 \mathrm{~s}$ averages (start and end times indicated by vertical dashed and solid black lines, respectively, a and c) of CAPS PMex and nephelometer data. Each numbered spectrum (e.g., SpEx_1) and 30 s average (e.g., AveCAPS_1 and AveNeph_1) in (b) and (d) correspond in order to each nonzero peak in (a) and $(\mathbf{c})$. 
shown. Similarly, error bars are omitted for CAPS PMex and nephelometer average data, however, the markers are scaled to approximate their $\pm 1 \sigma$ range. The two examples presented in Fig. 5 were chosen to illustrate the typically good agreement found between CAPS PMex and SpEx extinction. They also illustrate the small difference between extinction and scattering for aerosols that do not absorb light (e.g., PSL $903 \mathrm{~nm}$ ), versus the large difference found for aerosols that do absorb light (e.g., Aquadag).

Twenty-two aerosol tests were performed (Table S2) recording two to seven spectra in each test (typically three to four), resulting in a total of 87 spectra. SpEx data were averaged over $5 \mathrm{~nm}$ corresponding to each CAPS PMex wavelength in order to plot SpEx versus CAPS PMex extinctions (Fig. 6). Good agreement was found between these measurements with slopes near unity at all three wavelengths and $r^{2}$ values of $0.94-0.96$. These results, along with those of the $\mathrm{NO}_{2}$ and PSL tests, indicate that SpEx provides accurate spectral information within the precision of the instrument. A similar comparison between SpEx extinction and scattering measured by the TSI nephelometer for the purely scattering aerosol tests shows similarly good agreement (Fig. S3) with slopes near unity and $r^{2}$ values of $0.94-0.95$. Single scattering albedo values calculated from the nephelometer and SpEx data shown in Fig. S3 are given in Table S3.

\subsection{Comparison of normalized aerosol extinction spectra}

The magnitude of the extinctions measured for these aerosol tests ranged from $\sim 50$ to $500 \mathrm{Mm}^{-1}$ (Fig. 6), a reasonable range for polluted ambient conditions. In order to compare the shape of each spectrum with others from aerosols of similar size and different composition or of the same composition with different sizes, each spectrum was normalized such that the maximum extinction observed was scaled to a value of 1 (Fig. 7). A comparison of the PSL spectral shapes illustrates the shift of peak extinction from longer to shorter wavelengths with decreasing particle diameter from 903 to $200 \mathrm{~nm}$ (Fig. 7a). This is consistent with the expectation that particles interact most efficiently with wavelengths of light that are similar to their diameter. This is also evident in the AS and citric acid tests where data were obtained for 200 and $600 \mathrm{~nm}$ particle sizes (Fig. 7b).

Variability in the wavelength dependence of the spectra is also found among $600 \mathrm{~nm}$ particles of three different compositions (Fig. 7c). This variability in shape arises from differences in the refractive indices of these materials, along with some variability that may be due to minor differences in the size distributions (e.g., the high-spectral-resolution structure in the PSL spectrum arises from a nearly monodisperse size distribution, whereas the DMA size-selected AS, and citric acid particles were more broadly dispersed). Spectral comparisons of particles with a constant size illustrate the utility
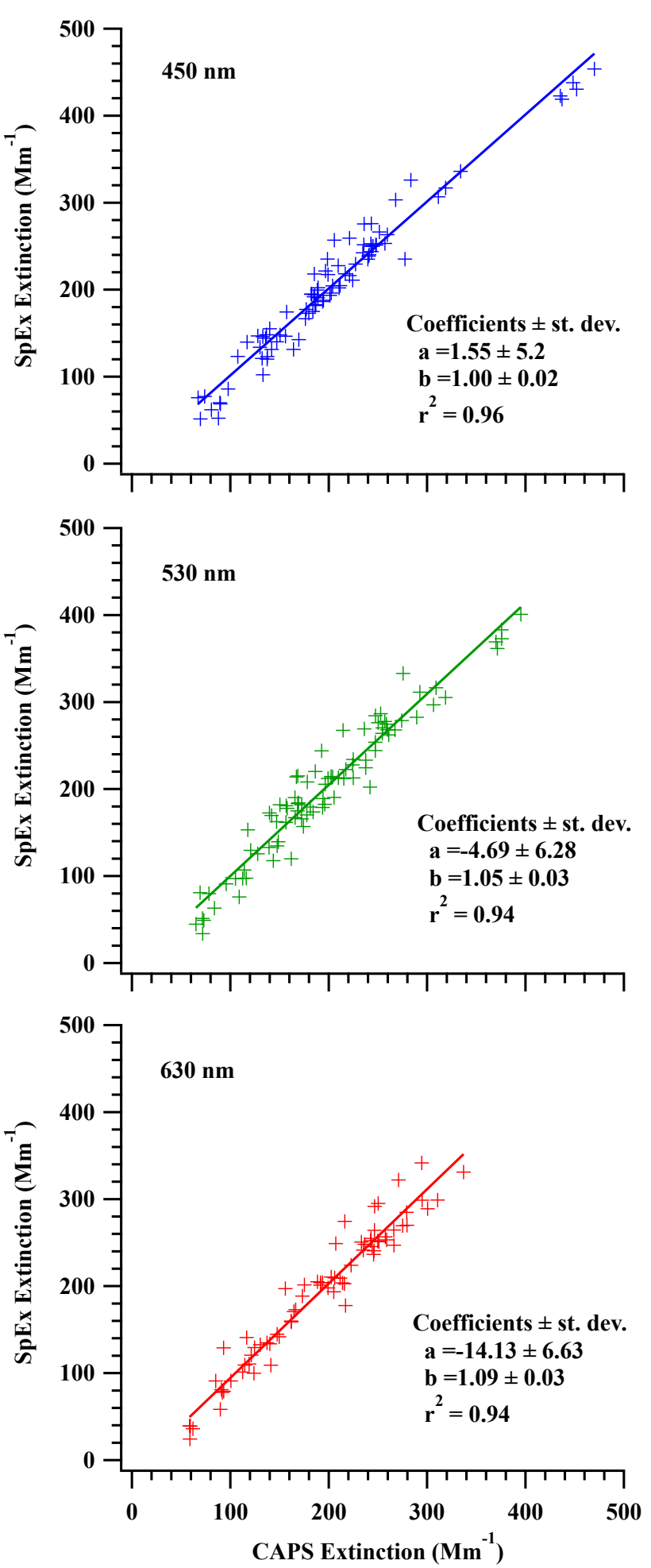

Figure 6. Extinctions measured at 450 (top panel), 530 (middle panel), and 630 (bottom panel) nm by SpEx versus by CAPS PMex (as shown in Fig. 5) for all aerosol tests listed in Table S2. Linear fits show the slope (b) and the intercept (a) in each case, along with $r^{2}$ values. 

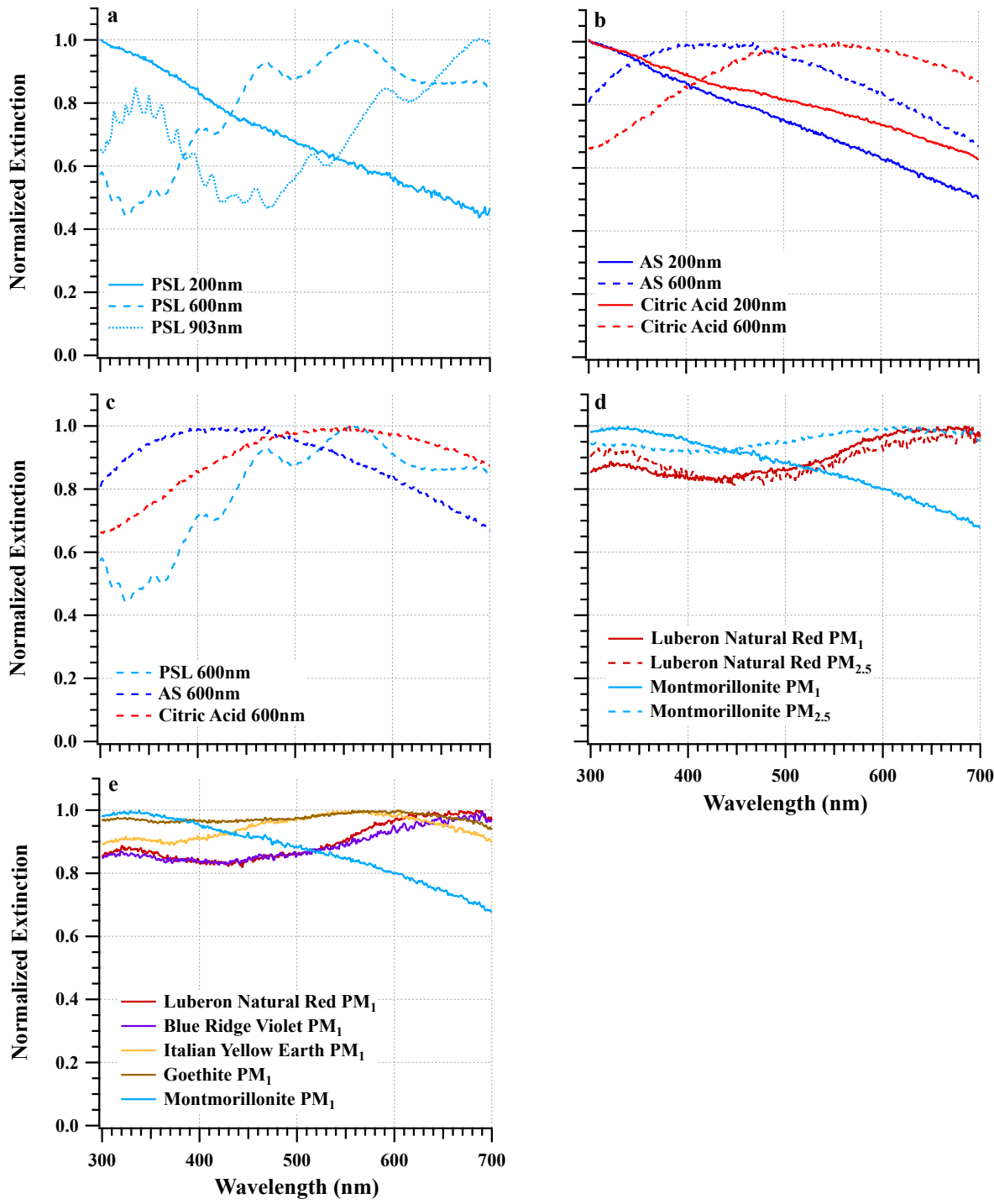

Figure 7. Normalized mean spectra (wavelength-corrected) from aerosol tests: PSL (a), AS and citric acid (b), montmorillonite and Luberon Natural Red dusts (d) as a function of particle size; $600 \mathrm{~nm}(\mathbf{c})$ and $\mathrm{PM}_{1}(\mathbf{e})$ as a function of aerosol composition.

of SpEx to measure spectral differences that arise from variability in chemical composition.

Dust particles are known to more efficiently extinguish light across all wavelengths and the SpEx spectra are consistent with this expectation (Fig. 7). Five powders (Table S2, Fig. 8) were used for $\mathrm{PM}_{1}$ size distribution tests, while only two (montmorillonite and Luberon Natural Red powders) were used for $\mathrm{PM}_{2.5}$ tests. Note, four of the five dust samples tested are sold as pigments; hence, their commercial names are used here (Natural Pigments, Willits, California). This particular set of dust samples was selected to represent a broad range of pigments (Fig. 8).

The extinction spectra for montmorillonite are consistent with the previous tests in that the maximum extinction is found at longer wavelengths for the larger particles (Fig. 7d).

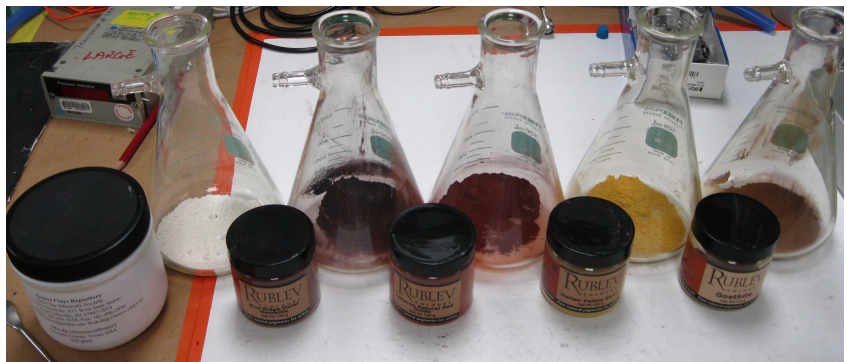

Figure 8. Pigmented dusts used in aerosol tests (from left to right: montmorillonite, Blue Ridge Violet, Luberon Natural Red, Italian Yellow Earth, goethite). 

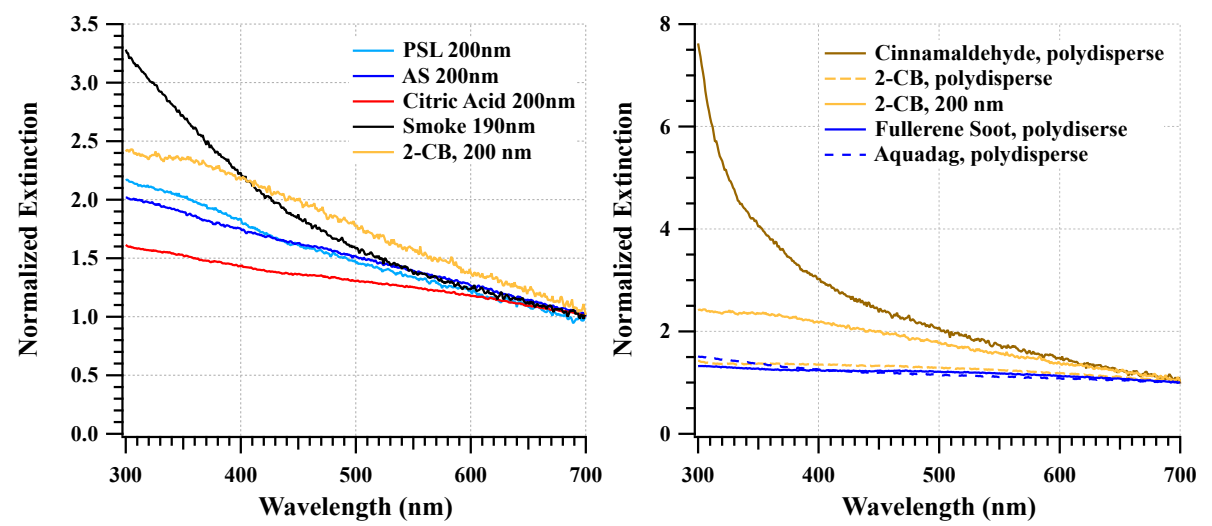

Figure 9. Normalized mean extinction spectra (wavelength-corrected) scaled to their values at $\lambda=700 \mathrm{~nm}$ for $\sim 200 \mathrm{~nm}$ particles (left panel) and brown carbon $(\mathrm{BrC})$ and black carbon $(\mathrm{BC})$ surrogate compounds (right panel).

However, for Luberon Natural Red, there is surprisingly little difference between the $\mathrm{PM}_{1}$ and $\mathrm{PM}_{2.5}$ spectra. This suggests the pigment of Luberon Natural Red affected the shape of the spectrum in both tests. Consider the extinction spectra for all five $\mathrm{PM}_{1}$ dust samples (Fig. 7e). Both Blue Ridge Violet and Luberon Natural Red exhibit peak extinctions between 600 and $700 \mathrm{~nm}$, consistent with the visibly reddish hue of these samples (Fig. 8), while both Italian Yellow Earth and goethite peak between 500 and $600 \mathrm{~nm}$. Only the bright white montmorillonite peaks at the short UV wavelengths. The brown colored goethite exhibits the smallest wavelength dependence in its spectrum, while montmorillonite exhibits the largest dependence. These results indicate that the mineral composition influences the spectral shape in addition to the dominant role of size distribution on extinction.

As is evident in Fig. 7, small particles exhibit extinction peaks at the shortest wavelengths measured by SpEx. Normalizing the mean curves to their maximum value (at $300 \mathrm{~nm}$ in the remaining tests performed) has the effect of visually suppressing the variability of such spectra in the UV region, while highlighting differences in the longer wavelength visible range. Since we are trying to investigate what aerosol information may be found in extinction spectra, particularly in the UV, we have scaled the rest of the normalized spectra to their values at $700 \mathrm{~nm}$. This scaling produces the effect of visually highlighting the differences in the spectral shapes in the UV (Fig. 9).

Not all of the materials used generated enough aerosol mass in the liquid nebulizer to allow for size selection. The slow flow rate of the DMA $\left(1-2 \mathrm{~L} \mathrm{~min}^{-1}\right)$ used for the size selection from the nebulized polydisperse aerosol leads to a highly diluted contribution in the $80 \mathrm{~L} \mathrm{~min}^{-1}$ air flow into the $17 \mathrm{~L}$ optical cell. Hence, $200 \mathrm{~nm}$ diameter particle spectra were only obtained for PSL, AS, citric acid, and 2carboxybenzaldehyde (2-CB), i.e., those materials that produced high concentrations of particles from which to select the $200 \mathrm{~nm}$ size range. The remaining spectra were obtained from the polydisperse size distributions generated from Fullerene soot, Aquadag, and cinnamaldehyde.

The $200 \mathrm{~nm}$ laboratory test aerosols from four different solutions all exhibit larger extinctions at $300 \mathrm{~nm}$ than $700 \mathrm{~nm}$, ranging from a factor of 1.6 to 2.4 larger (Fig. 9, left panel). In addition, $190 \mathrm{~nm}$ soot particles generated from a miniCAST instrument burning propane have an extinction $\sim 3.25$ times larger at 300 than $700 \mathrm{~nm}$. The extinctions obtained from polydisperse Fullerene soot, Aquadag, and 2-CB are $\sim 1.5$ times larger at 300 than $700 \mathrm{~nm}$. Unlike the other compounds tested, polydisperse cinnamaldehyde has a strongly curved spectrum where extinction at $300 \mathrm{~nm}$ is 7.5 times larger than at $700 \mathrm{~nm}$ (Fig. 9, right panel). The shape of this spectrum is suggestive, especially since cinnamaldehyde has a molecular structure consistent with expectations for a $\mathrm{BrC}$ compound. The characteristic trait of $\mathrm{BrC}$ is strongly enhanced absorption in the UV spectral range. Given the variable sources of $\mathrm{BrC}$ and the differing photochemical fates of the diverse chemical compounds that are likely to contribute to $\mathrm{BrC}$ (e.g., Lee et al., 2014; Laskin et al., 2015), there is no widely adopted standard $\mathrm{BrC}$ surrogate. Both $2-\mathrm{CB}$ and cinnamaldehyde were tested here specifically to try to identify a possible $\mathrm{BrC}$ surrogate (based on Scheme 1 in Lee et al., 2014). Of the two, cinnamaldehyde exhibits the curvature that might arise from enhanced UV absorption (assuming that absorption contributes a significant fraction to the extinction at the lower UV wavelengths). For the rest of this discussion, we will treat cinnamaldehyde as a $\mathrm{BrC}$ surrogate compound.

To test the spectral shapes of soot generated from propane in the mini-CAST, two settings were used that generated either more or less oxygen in the soot based on the work of Moore et al. (2014). Neither is strictly brown or black carbon, but one has a higher O:C ratio than the other. Small particles, $\sim 40 \mathrm{~nm}$ in diameter, were generated in both tests. As expected the "high" O:C soot exhibits enhanced UV extinction (via absorption) compared to the "low" $\mathrm{O}: \mathrm{C}$ soot 
Table 1. Extinction Ångström exponents calculated for the compounds in Fig. 10 based on visible wavelengths that can be measured by current commercially available instrumentation and UV/visible wavelengths which can be measured by SpEx.

\begin{tabular}{lccccccc}
\hline & CAPS PMex wavelengths & $\begin{array}{c}\text { Difference } \\
\text { (absolute) }\end{array}$ & $\begin{array}{c}\text { CAPS PMex } \\
\text { wavelengths }\end{array}$ & $\begin{array}{c}\text { SpEx } \\
\text { wavelengths }\end{array}$ & $\begin{array}{c}\text { Difference } \\
\text { (absolute) }\end{array}$ & $\begin{array}{c}\text { Fit to all } \\
\text { SpEx data }\end{array}$ \\
\hline Wavelengths & 450 and 530 & 530 and 630 & - & 450 and 530 & 300 and 530 & - & $300-700$ \\
\hline Fullerene & 0.18 & 0.51 & 0.33 & 0.18 & 0.18 & 0.00 & 0.19 \\
Aquadag & 0.32 & 0.38 & 0.06 & 0.32 & 0.50 & 0.18 & 0.56 \\
Low O:C soot & 0.65 & 0.56 & 0.09 & 0.65 & 0.76 & 0.11 & 0.94 \\
High O:C soot & 1.07 & 0.86 & 0.21 & 1.07 & 1.17 & 0.10 & 1.26 \\
Cinnamaldehyde & 1.71 & 1.84 & 0.14 & 1.71 & 2.50 & 0.79 & 2.20 \\
\hline
\end{tabular}

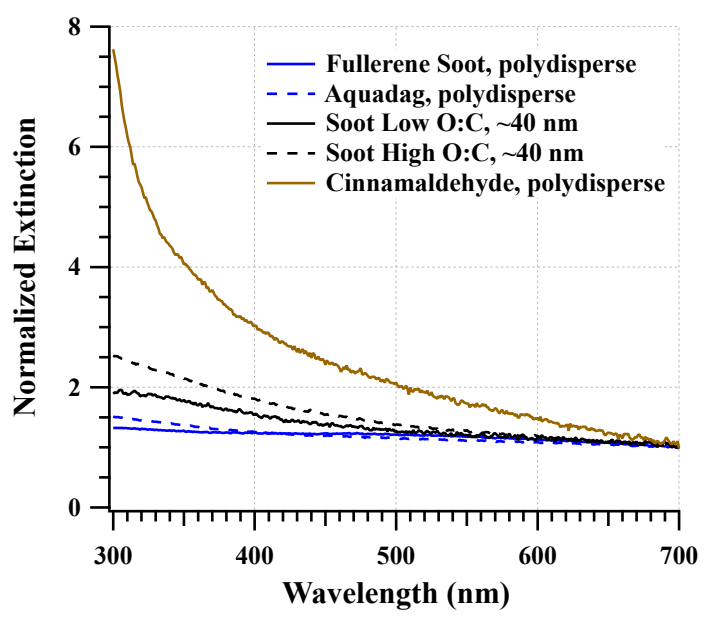

Figure 10. Normalized mean extinction spectra (wavelengthcorrected) scaled to their values at $\lambda=700 \mathrm{~nm}$ for two smoke tests with relatively higher or lower $\mathrm{O}: \mathrm{C}$ ratios in the soot particles, with the former expected to contain more $\mathrm{BrC}$ than the latter. Cinnamaldehyde is used as a $\mathrm{BrC}$ reference.

(Fig. 10). Here, both soot tests show greater enhancement at $300 \mathrm{~nm}$ than observed for either BC surrogate (Fullerene soot or Aquadag), which is not surprising given the smaller particle size generated by the propane flame. Neither soot test is as strongly enhanced as cinnamaldehyde, even given its larger particle size. While the comparison between the two soot tests should reflect differences in composition, some of the difference among the three polydisperse curves undoubtedly arises from size distribution differences. Hence the comparison here is mainly to illustrate the different spectral shapes expected for $\mathrm{BC}$ and $\mathrm{BrC}$ when absorption makes a significant contribution to the extinction signal and to use the surrogates simply to provide context for the $40 \mathrm{~nm}$ soot tests.

As discussed in the introduction, historically the extinction spectrum has been described with an inverse power law relationship with wavelength as in Eq. (1) (Ångström, 1929; Moosmüller and Chakrabarty, 2011). An Ångström exponent can be calculated based on any pair of wavelengths via Eq. (2) and should be constant if extinction is truly power- dependent. Extinction Ångström exponents $\left(\alpha_{\text {ext }}\right)$ calculated from two pairs of SpEx wavelengths (chosen to match those measured by CAPS PMex: 450 and $530 \mathrm{~nm}$, and 530 and $630 \mathrm{~nm}$ ) for the compounds shown in Fig. 10, clearly exhibit some variability in $\alpha_{\text {ext }}$ depending on the wavelength pair (Table 1). The differences between the two visible wavelength pairs range from 0.06 to 0.33 (Table 1). Taking advantage of the capability of SpEx to measure into the UV down to $300 \mathrm{~nm}$, these visible wavelength pairs may also be compared to a UV-visible wavelength pair, e.g., 300 and $530 \mathrm{~nm}$ (Table 1). Absolute $\alpha_{\text {ext }}$ differences between the 450, $530 \mathrm{~nm}$ pair and a SpEx-enabled 300, $530 \mathrm{~nm}$ pair were small for the BC surrogates (0.00-0.18) but significant for the BrC surrogate (cinnamaldehyde, 0.79). This result supports prior studies (e.g., Eck et al., 1999; Schuster et al., 2006) indicating that for some aerosols, mathematical descriptions other than power laws may better describe the spectral shape of $\alpha_{\text {ext }}$.

In addition to calculating $\alpha_{\text {ext }}$ for particular wavelength pairs, power law line fits were performed for the mean spectrum obtained from each aerosol test. Here, we modify Eq. (1) for the fitting as $\sigma_{\text {ext }}(\lambda)=A \lambda^{\alpha}$ where typically $A \sim 1$ and $\alpha$ is constrained to always be negative. Power laws are typically used when decades of data are spanned in log-log space over the relevant intervals in $x$ and $y$. However, over $300-700 \mathrm{~nm}$ in wavelength, none of the test data spanned more than a decade. Most of the tests in log-log space exhibit only a narrow range of extinction and nearly all of the test spectra exhibit curvature. This curvature is why $\alpha_{\text {ext }}$ is sensitive to the choice of wavelength pairs used in its calculation. In all cases polynomials provided a better fit to the data than power law functions. If a data set is well fit by a mathematical function, then the residuals (values resulting from subtracting the fit values from the raw data values) should reflect random noise distributed around zero. If the residuals exhibit a trend, then the function used is not a good fit to the data. In all cases, the power law fit residuals exhibited trends, whereas polynomial fits of order 7-10 provided good fits with residuals exhibiting random noise (e.g., Fig. 11). These results suggest that the spectra obtained carry more information than can be conveyed by a power law fit and that examination of features in certain spectral ranges (e.g., in the UV for identification of 

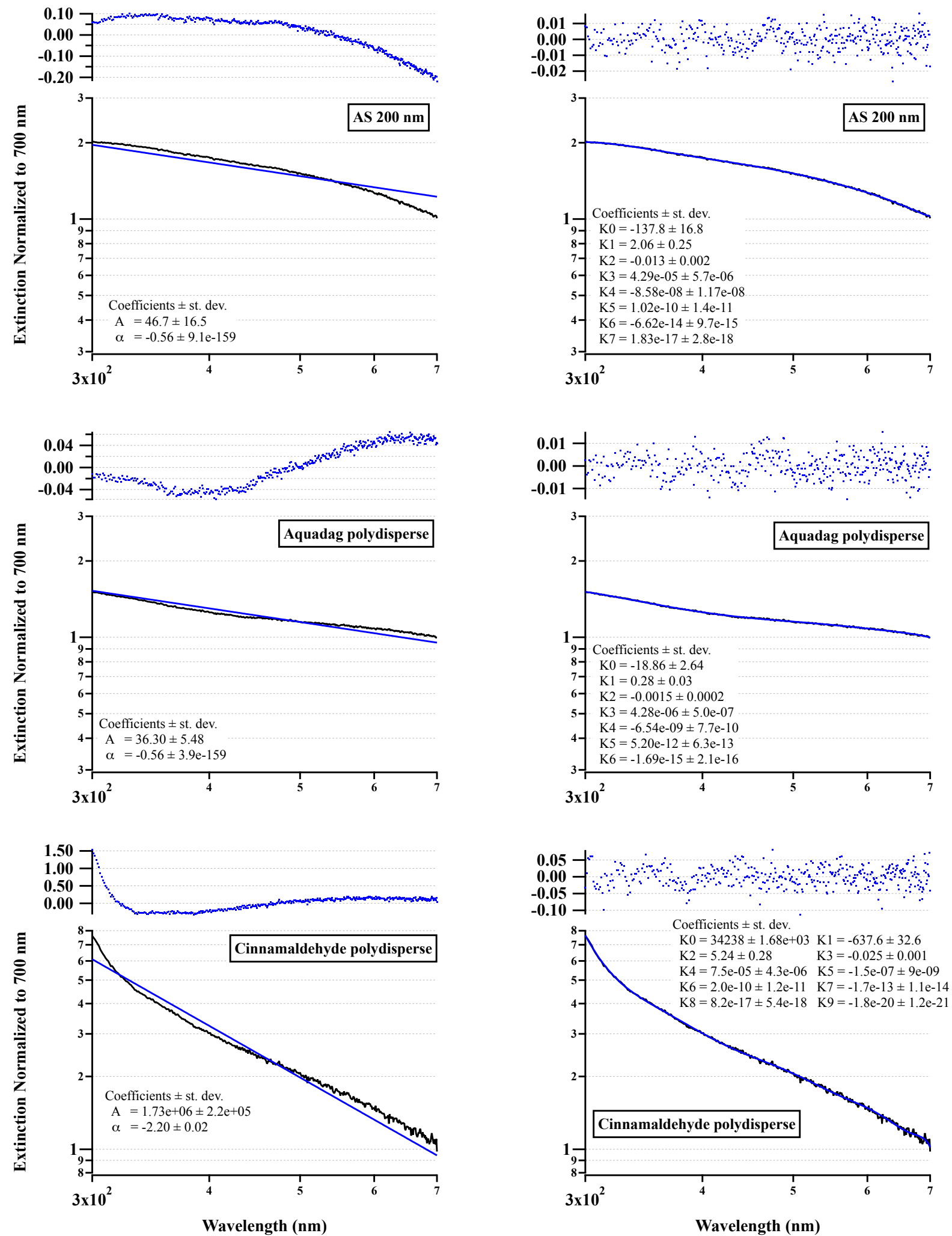

Figure 11. Curve fits (blue solid lines) applied to SpEx mean extinctions normalized to $700 \mathrm{~nm}$ (black solid lines). Power law fits (left panels) and polynomial fits (right panels) for AS $200 \mathrm{~nm}$ (top panels), polydisperse Aquadag (middle panels), and polydisperse cinnamaldehyde (bottom panels). Fit residuals (blue dots) are plotted above each curve fit. The residual is calculated by subtracting the fit function value from the raw data value; hence, the units are the same as the normalized extinctions. 
$\mathrm{BrC}$ ) may offer greater insight into the characteristics of the aerosols when measured with SpEx.

\section{Conclusions}

A new instrument, the spectral aerosol extinction $(\mathrm{SpEx})$ instrument, for the measurement of ambient aerosol extinction spectra over the $300-700 \mathrm{~nm}$ wavelength range has been described and characterized in the laboratory with $\mathrm{NO}_{2}$ and a variety of aerosols, generated from nonabsorbing materials, dusts, smoke, and $\mathrm{BC}$ and $\mathrm{BrC}$ analogs. SpEx is still under development with ongoing work to further reduce noise, improve precision, and reduce the detection limit. It is anticipated that prior to the next field deployment, the detection limits of individual spectra will be significantly reduced. Nonetheless, as reported herein SpEx performed well in all laboratory tests.

Good agreement with theoretical calculations for $\mathrm{NO}_{2}$ and PSL spheres was found. Correlations between SpEx and CAPS PMex extinction measurements at 450, 530, and $630 \mathrm{~nm}$ showed good agreement for all of the aerosol tests with $r^{2}$ values of 0.94-0.96. The aerosol test results reveal distinct differences in the spectral shapes obtained from the aerosols both as a function of size and composition. These results suggest that measurements of extinction spectra of ambient aerosols may also reveal unique characteristics related to size and composition over this wavelength range.

Polynomials were found to fit the measured spectra better than power laws due to the curvature of the spectra. This result indicates that detailed spectral information as provided by $\mathrm{SpEx}$ may offer greater insight into aerosol characteristics than can be obtained from commercially available instruments that make measurements at only a few wavelengths. The observed spectral curvature resulted in differences in $\alpha_{\text {ext }}$ depending on the wavelength pair used in calculations based on Eq. (2), as well as that obtained from a power law fit to the spectrum. In some cases the differences were small, suggesting extrapolation of $\alpha_{\text {ext }}$ into the UV from paired visible wavelengths may be acceptable, but large differences found for the $\mathrm{BrC}$ surrogate indicate extrapolation cannot be applied to such materials. With its lower wavelength limit of $300 \mathrm{~nm}$, SpEx will facilitate exploration of spectral UV optical characteristics.

SpEx is similar in some respects to the broadband cavityenhanced spectroscopy (BBCES) instrument (Washenfelder et al., 2013, 2015). BBCES has been used in the laboratory to retrieve wavelength-dependent complex refractive indices $(m(\lambda))$ for specific aerosols (Washenfelder et al., 2013) and it has been used in the field to perform an optical closure study to assess the contribution of scattering to extinction, as well as the contribution of $\mathrm{BC}$ and $\mathrm{BrC}$ to aerosol absorption at $365 \mathrm{~nm}$ (Washenfelder et al., 2015). Further in the latter study they found in rural Alabama in summer that $\mathrm{BrC}$ mass was principally associated with biomass burning; biogenic SOA contributed only a minor fraction. Note, their source apportionment relied both on BBCES measurements and absorption measurements obtained with the PILS-LWCC (Particle Into Liquid Sampler coupled to a Liquid Waveguide Capillary Cell). BBCES uses two cavities with light emitting diode sources that offer a combined spectral range of 355-420 nm (Washenfelder et al., 2015). The smaller cavities (each with an approximately $1.5 \mathrm{~L}$ volume), slower flow rate, and lower detection limit makes BBCES more suitable than SpEx for retrievals of $m(\lambda)$ due to the need to size select aerosols to perform the retrieval. Although we anticipate using SpEx in closure studies for specific wavelengths similar to that performed by Washenfelder et al. (2015), its real power lies in its ability to obtain detailed aerosol spectra over a wide spectral range.

When applied to ambient aerosol populations, it is anticipated that this spectral measurement capability will provide a novel tool for characterizing aerosols, enabling investigations of their optical evolution in the ambient environment. SpEx is a rack mountable instrument that may be deployed in mobile laboratories allowing for studies of the optical evolution of extinction as fresh emissions are transported downwind from sources. Such measurements offer a complement to related extant in situ measurements of aerosol chemical, physical, and optical properties. For example, SpEx extinction spectra coupled with PILS-LWCC absorption spectra will allow for the calculation of scattering spectra, single-scattering albedo spectra, and other spectral optical properties. This instrument for measuring in situ aerosols also offers a new measurement capability for calibration and validation studies of aerosol retrievals from remote sensors.

In a recent review of $\mathrm{BrC}$ (Laskin et al., 2015), results from studies examining the role of absorbing aerosols on photolysis rates of atmospheric gases and biogenic gas emissions were reported that offer additional intriguing possibilities for the utility of the spectral information that can be obtained with SpEx. By acquiring data on aerosol light extinction down to $300 \mathrm{~nm}$ in the ambient environment, SpEx may help inform our understanding of how UV-absorbing aerosols influence the photochemical environment for ambient gases (i.e., via their potential to reduce photolysis rates) and affect biogenic emissions of gases such as isoprene by altering the light environment. In their discussion of aerosol absorption, Laskin et al. (2015) note that wavelength-resolved measurements are rare and are preferable to assumed power law wavelength dependencies. SpEx will help address the need for more wavelength-resolved measurements to examine the complex interactions in our ambient atmosphericbiogeochemical environment.

\section{The Supplement related to this article is available online at doi:10.5194/amt-8-4755-2015-supplement.}


Acknowledgements. The authors thank Kevin Kaye, Tom Wisniewski, John Hair, John Prohaska, Brian Heikes, Matt Brown, James Hite, and Gao Chen for helpful comments and suggestions during this project. C. E. Jordan is particularly grateful to John Daniel for his encouragement and support of this work, funded by NOAA grant no. NA10OAR4590134.

Edited by: V. Amiridis

\section{References}

Alfaro, S. C., Lafon, S., Rajot, L., Formenti, P., Gaudichet, A., and Maille, M.: Iron oxides and light absorption by pure desert dust: an experiment study, J. Geophys. Res., 109, D08208, doi:10.1029/2003JD004374, 2004.

Anderson, T. L. and Ogren, J. A.: Determining aerosol radiative properties using the TSI 3563 integrating nephelometer, Aerosol Sci. Tech., 29, 57-69, doi:10.1080/02786829808965551, 1998.

Andreae, M. O. and Gelencsér, A.: Black carbon or brown carbon? The nature of light-absorbing carbonaceous aerosols, Atmos. Chem. Phys., 6, 3131-3148, doi:10.5194/acp-6-3131-2006, 2006.

Ångström, A.: On the atmospheric transmission of sun radiation and on dust in the air, Geogr. Ann. A, 11, 156-166, 1929.

Apicella, B., Alfe, M., Barbella, R., Tegrossi, A., and Ciajolo, A.:Aromatic structures of carbonaceous materials and soot inferred by spectroscopic analysis, Carbon, 42, 1583-1589, 2004.

Baumgardner, D., Popovicheva, O., Allan, J., Bernardoni, V., Cao, J., Cavalli, F., Cozic, J., Diapouli, E., Eleftheriadis, K., Genberg, P. J., Gonzalez, C., Gysel, M., John, A., Kirchstetter, T. W., Kuhlbusch, T. A. J., Laborde, M., Lack, D., Müller, T., Niessner, R., Petzold, A., Piazzalunga, A., Putaud, J. P., Schwarz, J., Sheridan, P., Subramanian, R., Swietlicki, E., Valli, G., Vecchi, R., and Viana, M.: Soot reference materials for instrument calibration and intercomparisons: a workshop summary with recommendations, Atmos. Meas. Tech., 5, 1869-1887, doi:10.5194/amt-5-1869-2012, 2012.

Beyersdorf, A. J., Timko, M. T., Ziemba, L. D., Bulzan, D., Corporan, E., Herndon, S. C., Howard, R., Miake-Lye, R., Thornhill, K. L., Winstead, E., Wey, C., Yu, Z., and Anderson, B. E.: Reductions in aircraft particulate emissions due to the use of Fischer-Tropsch fuels, Atmos. Chem. Phys., 14, 11-23, doi:10.5194/acp-14-11-2014, 2014.

Bond, T. C. and Bergstrom, R. W.: Light absorption by carbonaceous particles: an investigative review, Aerosol Sci. Tech., 40, 27-67, 2006.

Bond, T. C., Doherty, S. J., Fahey, D. W., Forster, P. M., Berntsen, T., DeAngelo, B. J., Flanner, M. G., Ghan, S., Kärcher, B., Koch, D., Kinne, S., Kondo, Y., Quinn, P. K., Sarofim, M. C., Schultz, M. G., Schulz, M., Venkataraman, C., Zhang, H., Zhang, S., Bellouin, N., Guttikunda, S. K., Hopke, P. K., Jacobson, M. Z., Kaiser, J. W., Klimont, Z., Lohmann, U., Schwarz, J. P., Shindell, D., Storelvmo, T., Warren, S. G., and Zender, C. S.: Bounding the role of black carbon in the climate system: a scientific assessment, J. Geophys. Res.Atmos., 118, 5380-5552, doi:10.1002/jgrd.50171, 2013.
Bones, D. L., Henricksen, D. K., Mang, S. A., Gonsior, M., Bateman, A. P., Nguyen, T. B., Cooper, W. J., and Nizkorodov, S. A.: Appearance of strong absorbers and fluorophores in limonene- $\mathrm{O}_{3}$ secondary organic aerosol due to $\mathrm{NH}_{4}^{+}$mediated chemical aging, J. Geophys. Res., 115, D05203, doi:10.1029/2009JD012864, 2010.

Chartier, R. T.: Aerosol extinction measurements with a new multipass aerosol differential optical absorption spectrometer (ADOAS): Laboratory validation and initial ambient measurements, MS Thesis, University of New Hampshire, Durham, NH, 2010.

Chartier, R. T. and Greenslade, M. E.: Initial investigation of the wavelength dependence of optical properties measured with a new multi-pass Aerosol Extinction Differential Optical Absorption Spectrometer (AE-DOAS), Atmos. Meas. Tech., 5, 709-721, doi:10.5194/amt-5-709-2012, 2012.

Chen, Y. and Bond, T. C.: Light absorption by organic carbon from wood combustion, Atmos. Chem. Phys., 10, 1773-1787, doi:10.5194/acp-10-1773-2010, 2010.

Desyaterik, Y., Sun, Y., Shen, X., Lee, T., Wang, X., Wang, T., and Collett Jr., J. L.: Speciation of "brown" carbon in cloud water impacted by agricultural biomass burning in eastern China, J. Geophys. Res.-Atmos., 118, 7389-7399, doi:10.1002/jgrd.50561, 2013.

Eck, T. F., Holben, B. N., Reid, J. S., Dubovik, O., Smirnov, A., O’Neill, N. T., Slutsker, I., and Kinne, S.: Wavelength dependence of the optical depth of biomass burning, urban, and desert dust aerosols, J. Geophys. Res., 104, 31333-31349, 1999.

Gysel, M., Laborde, M., Olfert, J. S., Subramanian, R., and Gröhn, A. J.: Effective density of Aquadag and fullerene soot black carbon reference materials used for SP2 calibration, Atmos. Meas. Tech., 4, 2851-2858, doi:10.5194/amt-4-2851-2011, 2011.

Hecobian, A., Zhang, X., Zheng, M., Frank, N., Edgerton, E. S., and Weber, R. J.: Water-Soluble Organic Aerosol material and the light-absorption characteristics of aqueous extracts measured over the Southeastern United States, Atmos. Chem. Phys., 10, 5965-5977, doi:10.5194/acp-10-5965-2010, 2010.

IPCC: Climate Change 2007: The Physical Science Basis. Contribution of Working Group I to the Fourth Assessment Report of the Intergovernmental Panel on Climate Change, edited by: Solomon, S., Qin, D., Manning, M., Chen, Z., Marquis, M., Averyt, K. B., Tignor, M., and Miller, H. L., Cambridge University Press, Cambridge, UK and New York, US, 27-30, 2007.

IPCC: Climate Change 2014: Synthesis Report, edited by: The Core Writing Team, Pachauri, R. K., Meyer, L., available on-line in unedited form at: http://www.ipcc.ch/report/ar5/syr/, p. 43, 2014.

Jacobson, M. Z.: Isolating nitrated and aromatic aerosols and nitrated aromatic gases as sources of ultraviolet light absorption, J. Geophys. Res., 104, 3527-3542, 1999.

Jaoui, M., Edney, E. O., Kleindienst, T. E., Lewandowski, M., Offenberg, J. H., Surratt, J. D., and Seinfeld, J. H.: Formation of secondary organic aerosol from irradiated $\alpha$-pinene/toluene $/ \mathrm{NO}_{\mathrm{x}}$ mixtures and the effect of isoprene and sulfur dioxide, J. Geophys. Res., 113, D09303, doi:10.1029/2007JD009426, 2008.

Kumar, P., Sokolik, I. N., and Nenes, A.: Measurements of cloud condensation nuclei activity and droplet activation kinetics of fresh unprocessed regional dust samples and minerals, Atmos. 
Chem. Phys., 11, 3527-3541, doi:10.5194/acp-11-3527-2011, 2011.

Laskin, A., Laskin, J., and Nizkorodov, S. A.: Chemistry of atmospheric brown carbon, Chem. Rev., 115, 4335-4382, doi:10.1021/cr5006167, 2015.

Lee, H. J., Aiona, P. K., Laskin, A., Laskin, J., and Nizkorodov, S. A.: Effect of solar radiation on the optical properties and molecular composition of laboratory proxies of atmospheric brown carbon, Environ. Sci. Technol., 48, 10217-10226, doi:10.1021/es502515r, 2014.

Moore, R. H., Ziemba, L. D., Dutcher, D., Beyersdorf, A. J., Chan, K., Crumeyrolle, S., Raymond, T. M., Thornhill, K. L., Winstead, E. L., and Anderson, B. E.: Mapping the operation of the miniature combustion aerosol standard (MiniCAST) soot generator, Aerosol Sci. Tech., 48, 467-479, doi:10.1080/02786826.2014.890694, 2014.

Moosmüller, H. and Chakrabarty, R. K.: Technical Note: Simple analytical relationships between Ångström coefficients of aerosol extinction, scattering, absorption, and single scattering albedo, Atmos. Chem. Phys., 11, 10677-10680, doi:10.5194/acp-1110677-2011, 2011.

Moosmüller, H., Chakrabarty, R. K., and Arnott, W. P.: Aerosol light absorption and its measurement: a review, J. Quant. Spectrosc. Ra., 110, 844-878, doi:10.1016/j.jqsrt.2009.02.035, 2009.

Schuster, G. L., Dubovik, O., and Holben, B. N.: Ångström exponent and bimodal aerosol size distributions, J. Geophys. Res., 111, D07207, doi:10.1029/2005JD006328, 2006.

Seinfeld, J. H. and Pandis, S. N.: Atmospheric Chemistry and Physics, From Air Pollution to Climate Change, published by John Wiley \& Sons, New York, USA, 1326 pp., 1998.

Sokolik, I. N. and Toon, O. B.: Incorporation of mineralogical composition into models of the radiative properties of mineral aerosol from UV to IR wavelengths, J. Geophys. Res., 104, 9423-9444, 1999.
Washenfelder, R. A., Flores, J. M., Brock, C. A., Brown, S. S., and Rudich, Y.: Broadband measurements of aerosol extinction in the ultraviolet spectral region, Atmos. Meas. Tech., 6, 861-877, doi:10.5194/amt-6-861-2013, 2013.

Washenfelder, R. A., Attwood, A. R., Brock, C. A., Guo, H., Xu, L., Weber, R. J., Ng, N. L., Allen, H. M., Ayres, B. R., Baumann, K., Cohen, R. C., Draper, D. C., Duffey, K. C., Edgerton, E., Fry, J. L., Hu, W. W., Jimenez, J. L., Palm, B. B., Romer, P., Stone, E. A., Wooldridge, P. J., and Brown, S. S.: Biomass burning dominates brown carbon absorption in the rural southeastern United States, Geophys. Res. Lett., 42, 653-664, doi:10.1002/2014GL062444, 2015.

White, J. U.: Long optical paths of large aperture, J. Opt. Soc. Am., 32, 285-288, 1942.

Yang, M., Howell, S. G., Zhuang, J., and Huebert, B. J.: Attribution of aerosol light absorption to black carbon, brown carbon, and dust in China - interpretations of atmospheric measurements during EAST-AIRE, Atmos. Chem. Phys., 9, 2035-2050, doi:10.5194/acp-9-2035-2009, 2009.

Zhang, X., Lin, Y.-H., Surratt, J. D., Zotter, P., Prévôt, A. S. H., and Weber, R. J.: Light-absorbing soluble organic aerosol in Los Angeles and Atlanta: a contrast in secondary organic aerosol, Geophys. Res. Lett., 38, L21810, doi:10.1029/2011GL049385, 2011.

Zhang, X., Lin, Y.-H., Surratt, J. D., and Weber, R. J.: Sources, composition and Absorption Ångström Exponent of lightabsorbing organic components in aerosol extracts from the Los Angeles Basin, Environ. Sci. Technol., 47, 3685-3693, doi:10.1021/es305047b, 2013. 